\title{
SISTEM PENANDA KEPEMILIKAN FILE DOKUMEN MENGGUNAKAN METODE DIGITAL WATERMARK PADA FILE PENELITIAN DOSEN UNIVERSITAS MUSLIM INDONESIA
}

\author{
Yulita Salim ${ }^{1)}$, Huzain Azis ${ }^{2}$ \\ 1)yulita.salim@umi.ac.id, ${ }^{2)}$ traiteurs@yahoo.co.id \\ 1,2 Universitas Muslim Indonesia Makassar
}

\begin{abstract}
Abstrak
UMI sebagai perguruan tinggi terbesar dan terbaik di Indonesia bagian timur memiliki database yang cukup besar, terutama pada database penelitian dosen. Banyaknya data yang tersimpan memiliki resiko adanya pengambilan dan pengakuan kepemilikan data khususnya data penelitian dosen. Penelitian ini bertujuan untuk merancang sebuah sistem yang dapat memberi penanda kepemilikan pada sebuah dokumen teks penelitian yang dapat digunakan oleh dosen di UMI. Metode penelitian yang dilakukan meliputi identifikasi masalah, studi literature mengenai file dokumen yang akan digunakan sebagai data uji dan metode Digital Watermark sebagai algoritma untuk penanda kepemilikan file dokumen yang diuji, desain aplikasi desktop menggunakan bahasa pemrograman Java dan MySQL sebagai database server. Hasil penelitian ini adalah sistem yang dapat digunakan dosen maupun pihak Lembaga Penelitian dan Pengembangan Sumber Daya (LP2S) UMI untuk memberi tanda kepemilikan pada dokumen agar dapat memberikan layanan tambahan dalam pengecekan kemiripan judul yang telah ada sebelumnya di LP2S.
\end{abstract}

Kata Kunci: File Dokumen, Steganography, Digital Watermarking

\section{Pendahuluan}

Teknologi yang semakin canggih telah memberi banyak kemudahan di masa kini, baik layanan penyimpanan data, komunikasi, maupun pertukaran data. Peningkatan penyebaran dokumen penelitian menunjukkan semakin besarnya minat para insan akademik untuk melakukan penelitian untuk pengembangan keilmuan di bidang masing-masing. Namun tidak adanya penanda pada dokumen penelitian justru menimbulkan kelemahan pada kesadaran terjadinya pengambilan hak kepemilikan dokumen penelitian tersebut. Dirjen DIKTI Kemendikbud Djoko Santoso mengakui masih adanya persoalan krusial dalam proses sertifikasi, salah satunya adalah masih adanya plagiarisme. Menurut data Kemendikbud, kasus plagiat atau biasa disebut copy paste pada proses sertifikasi dosen mencapai 808 kasus di tahun 2013 [1,2].

Salah satu metode steganography yang dapat digunakan untuk menghindari masalah tersebut, dapat menggunakan metode Digital Watermarking yaitu salah satu layanan keamanan steganografi untuk pemberian tanda kepemilikan sebuah data.

Berdasarkan pemaparan tersebut peneliti mencoba merancang sebuah perangkat lunak aplikasi sebagai salah satu cara untuk memberi penanda kepemilikan sebuah dokumen. Judul penelitian yang diangkat sesuai masalah tersebut diatas adalah Sistem Penanda Kepemilikan (Digital Watermark) pada Dokumen Teks. Data Sample yang akan digunakan dalam penelitian ini adalah dokumen penelitian Dosen UMI yang akan dipilih secara random, pada Lembaga Peneletian dan Pengembangan Sumber Daya Manusia UMI Makassar.

Steganografi (steganography) adalah seni dan ilmu menyembunyikan pesan rahasia di dalam pesan lain sehingga pesan rahasia tersebut tidak dapat diketahui. Pada teknologi komunikasi, data yang menjadi media tempat penyembunyian data rahasia merupakan data yang umum dikirimkan, dapat berupa teks, gambar, audio atau video, namun pada konsep baru dari steganografi atau biasa disebut network steganography yaitu steganografi yang menggunakan kontrol komunikasi protokol, elemen atau fungsi dasar telekomunikasi sebagai media atau host [4].

Beberapa standar terminologi yang digunakan pada steganografi :

1) Cover Medium, adalah data atau media yang akan digunakan sebagai tempat informasi rahasia di sembunyikan

2) Stego Medium atau Stego data, adalah data atau media yang telah berisi informasi rahasia

3) Message, adalah pesan atau informasi rahasia

4) Redundant bits, adalah bit-bit data dari cover medium yang dapat di modifikasi. 
Penelitian ini dikaji untuk mengetahui penerapan metode digital watermark sebagai sistem penanda kepemilikan dokumen teks pada file gambar berekstensi pdf.

Batasan masalah dalam perancangan penelitian ini adalah:

1) Data atau File Dokumen yang digunakan berekstensi pdf.

2) Data yang digunakan sebagai penanda dokumen adalah file Gambar.

3) Sistem dirancang sebagai Penanda Kepemilikan Dokumen Penelitian Dosen UMI.

\section{Metode}

\subsection{Tahap pelaksanaan penelitian}

1) Identifikasi Masalah, pada tahapan identifikasi masalah peneliti berusaha menguraikan permasalahan dalam pengelolaan penanda kepemilikan data penelitian dosen di LP2S UMI.

2) Desain Algoritma Watermark. Setelah tahap identifikasi masalah dilakukan melakukan desain algoritma yang akan digunakan untuk penandaan file dokumen penelitian.

3) Desain User Interface system berbasis desktop, kemudian dilakukan perancangan form-form yang dibutuhkan oleh sistem agar diperoleh output sesuai kebutuhan user.

4) Penerapan metode digital watermark pada bahasa pemrograman java, algoritma yang telah di desain sebelumnya kemudian di code kedalam bahasa pemrograman java untuk aplikasi desktop.

5) Pengumpulan data uji, data uji yang dikumpulkan adalah file dokumen penelitian dosen berupa softcopy dalam format pdf.

6) Proses Pengujian/Testing File Dokumen untuk pemberian tanda data kepemilikan menggunakan White Box Testing Application.

\subsection{Variabel yang diamati}

Variabel yang diamati dalam perancangan Document Marking System ini adalah File dokumen penelitian dosen UMI dan metode Watermarking sebagai metode penanda yang digunakan.

\subsection{Tahapan Watermarking}

Metode watermarking dapat dibagi dalam dua bagian, yaitu proses penyisipan dan proses ekstraksi (deteksi). [5]

Tahap penyisipan meliputi:

1. Memilih citra yang akan digunakan sebagai citra pembawa watermark.

2. Memilih citra yang akan dijadikan watermark.

3. Menentukan algoritma yang digunakan untuk penyisipan.

4. Membuat matriks penampung citra dan melakukan penyesuai untuk citra dan melakukan penyesuaian untuk citra watermark karena besarnya tidak sama dengan pembawa citra.

Tahap ekstraksi meliputi:

1. Memilih citra yang sudah disisipi watermark.

2. Menyediakan parameter yang dibutuhkan dalam ekstraksi.

3. Melakukan ekstraksi.

4. Mengembalikan citra watermark yang ukurannya disesuaikan dengan citra pembawa.

\section{Hasil dan Pembahasan}

Hasil penelitian ini adalah sebuah aplikasi atau sistem penanda kepemilikan dokumen penelitian. Rincian perancangan pada sistem ini peneliti membagi menjadi 3 tahap, tahap pertama yaitu instalasi plugin Software Development Kit, tahap kedua adalah instalasi Mysql sebagai database server dan tahap terakhir yaitu pengujian sistem. Berikut dijelaskan tentang tahapan instalasi dan konfigurasi, serta pengujian sistem yang telah dirancang.

1. Instalasi dan Konfigurasi MySQL

Mysql merupakan aplikasi sebagai database server atau tempat penyimpanan data sistem yang dirancang merupakan Mysql yang telah include dalam aplikasi XAMPP, untuk mengaktifkan layanan mysql yaitu dengan mengaktifkan xampp dan menekan tombol start untuk modul mysql seperti yang terlihat pada Gambar 1 [3]. 


\section{ILKOM Jurnal Ilmiah Volume 9 Nomor 2 Agustus 2017}

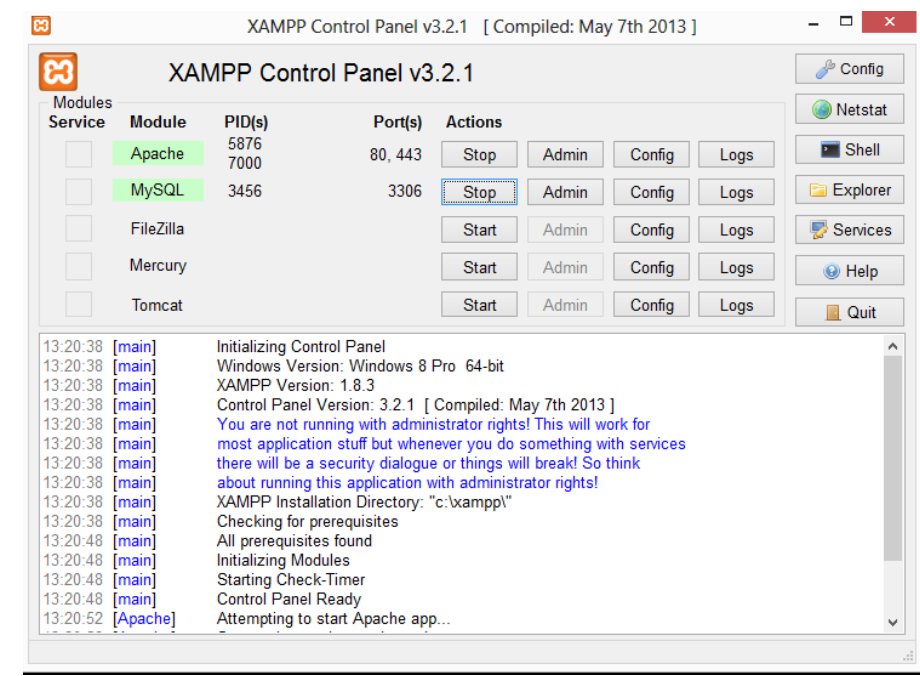

Gambar 1. Proses pengaktifan modul MySQL

\section{Pengujian sistem}

Sistem dirancang hanya terdiri dari 4 form, yaitu form login yang juga sebagai form menu utama, form Watermarking sebagai form input dan proses dan form preview sebagai form output. Gambar 2 menujukkan desain interface form login dan juga sebagai form menu utama

Pada form awal terdapat halaman login dan beberapa menu, menu watermark dan menu similarity, menu watermark dan similarity sifatnya disable atau tidak aktif. Form login dan menu utama sebagai form awal akan dilakukan koneksi langsung dengan database, data username dan sandi disimpan di dalam database, jika username dan password yang diinput sesuai dengan yang ada dalam database maka menu watermark dan similarity sifatnya akan berubah menjadi enable atau aktif.

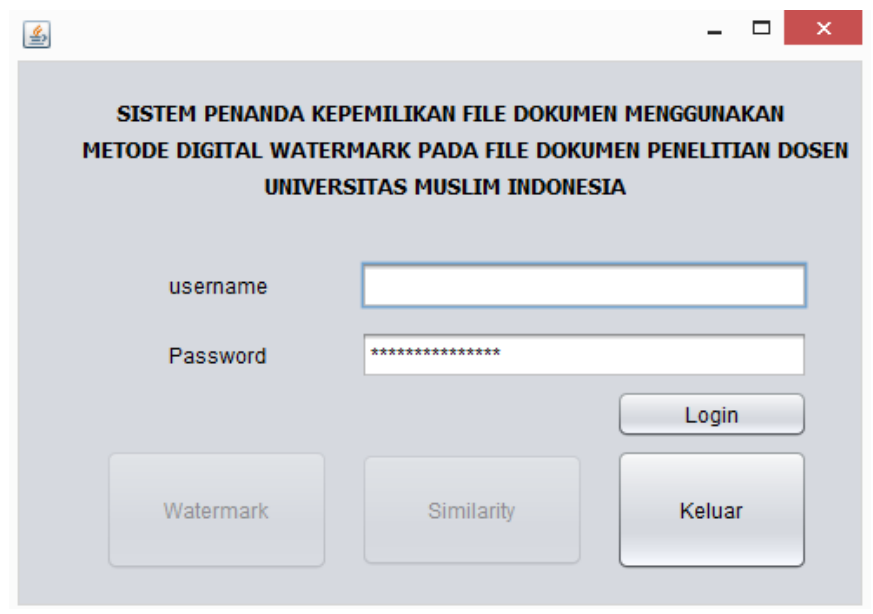

Gambar 2. Form Login dan Menu Utama

Proses form login dan menu utama tidak terdapat Error pada desain antar muka, proses koneksi database, dan event yang dikerjakan. Pada Gambar 3 menunjukkan desain form Watermarking . 


\section{ILKOM Jurnal Ilmiah Volume 9 Nomor 2 Agustus 2017}

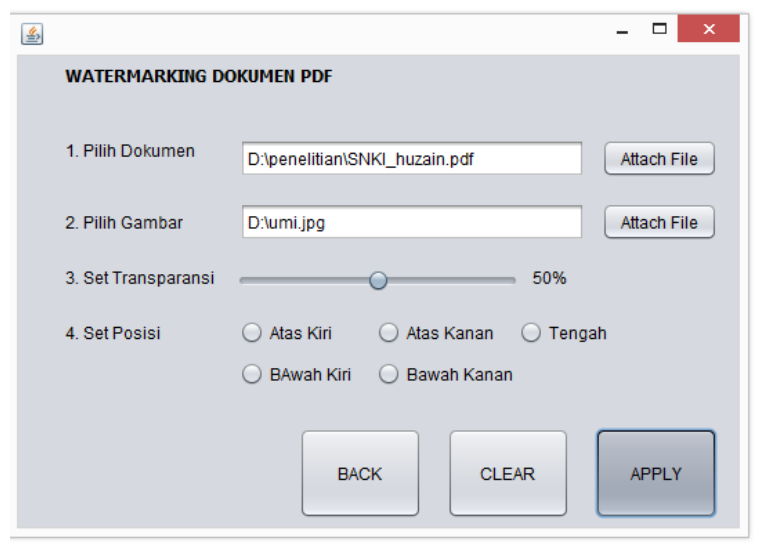

Gambar 3. Form Proses Watermarking Dokumen

Pada form Watermarking dokumen terdapat langkah-langkah urutan untuk melakukan proses watermark, pertama pilih dokumen penelitian yang berkestensi atau dengan format PDF, kemudian langkah kedua yaitu meimilih gambar yang akan dijadikan sebagai stegadata atau gambar yang akan disisipkan kesetiap halaman, kemudian langkah ketiga adalah set transparansi yaitu proses untuk mengatur keburaman gambar yang akan disisipkan dan proses terakhir adalah set posisi adalah menu untuk mengatur posisi gambar yang akan ditempatkan kedalam file pdf. Tiga tombol yang terdapat dalam form tersebut yaitu BACK Button untuk kembali kehalama utama, CLEAR Button untuk mengembalikan form Watermarking ke mode awal dan APPLY Button untuk mengeksekusi proses Watermarking sesuai inputan dan set yang telah dilakukan sebelumnya.

Pada form Watermarking tidak terdapat Error pada desain antar muka, proses koneksi database, dan event yang dikerjakan. Gambar 4 menggambarkan form preview dokumen sebelum dan setelah melalui proses Watermarking, serta memperlihatkan lama proses Watermarking dan status watermark yang berhasil maupun tidak.

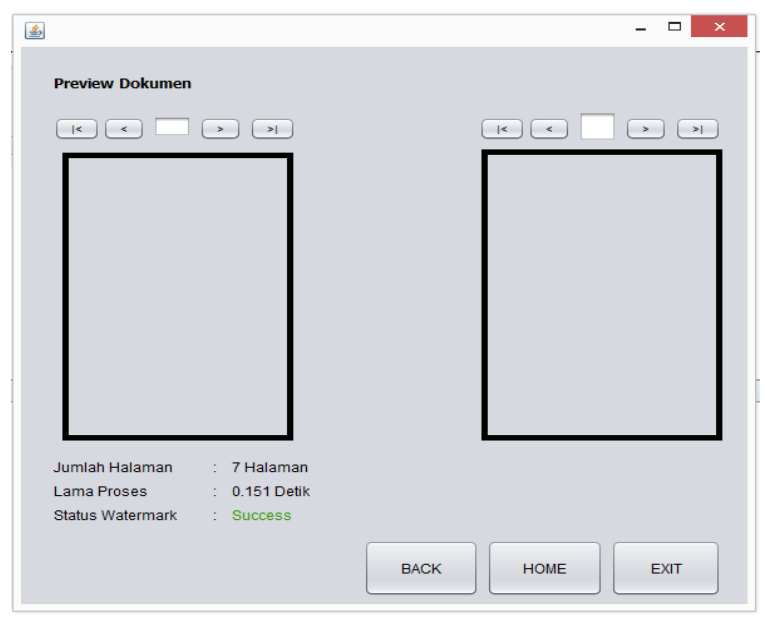

Gambar 4. Form Preview Dokumen

Form Similarity yang terlihat pada Gambar 4 merupakan layanan tambahan pada sistem untuk menyimpan data judul penelitian yang ada pada LP2S UMI, dan sebelum data disimpan layanan pengecekan similarity atau kesamaan judul juga bisa digunakan untuk mengecek seberapa mirip judul yang ada masukkan dengan judul judul yang telah di masukkan dalam sistem atau database sebelumnya. 


\section{ILKOM Jurnal Ilmiah Volume 9 Nomor 2 Agustus 2017}

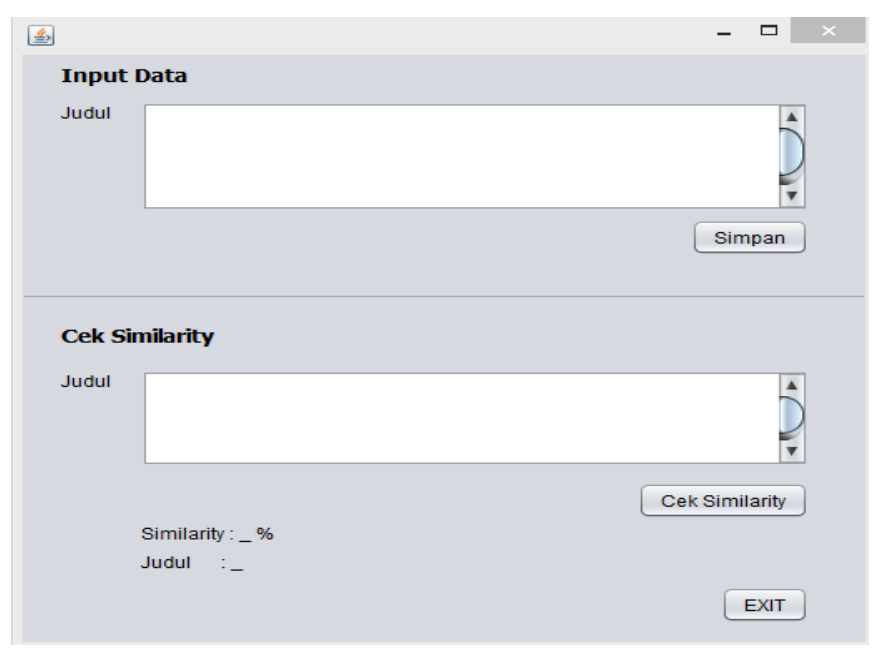

Gambar 5 Form Input dan Cek Similarity

Pada Gambar 5 menggambarkan dokumen sebelum dan setelah dilakukannya proses Watermarking. Dokumen penelitian (kanan) yang dimasukkan sebelumnya tidak memiliki latar atau hanya dokumen penelitian seperti biasanya, namun dengan menambahkan gambar sebagai Watermarking gambar tersebut akan menjadi latar disetiap halaman yang ada pada dokumen penelitian tersebut.

Form pada Gambar 4 dan Gambar 5 tidak terdapat Error pada desain antar muka, proses koneksi database, dan event yang dikerjakan.
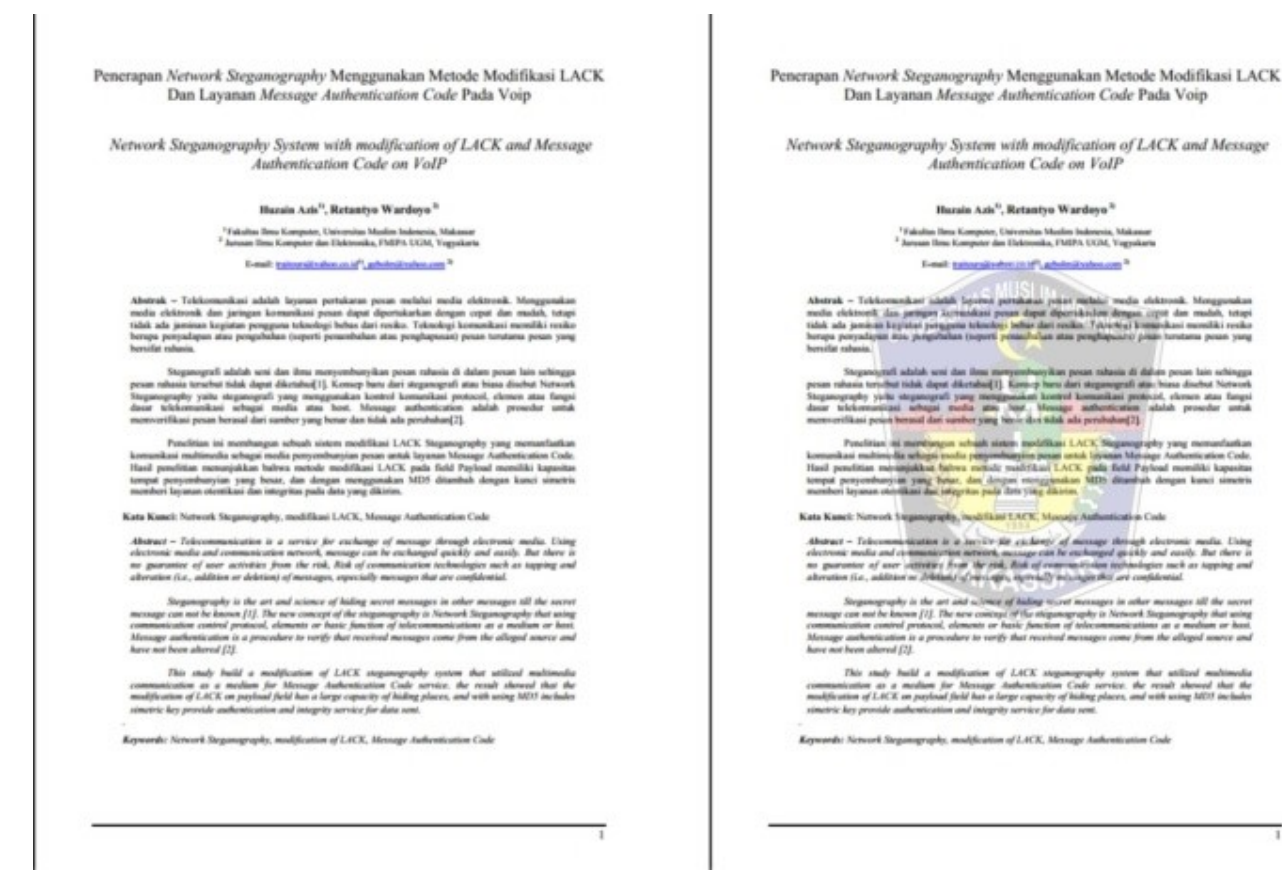

Gambar 6. Dokumen Sebelum (kiri) dan Setelah (Kanan) melalui proses Watermarking

Gambar 6 menunjukkan hasil ekstraksi dokumen. Pada gambar 6 sebelah kiri menunjukkan dokumen sebelum dilakukan proses watermarking dan gambar sebelah kanan menunjukkan dokumen setelah dilakukan proses watermarking. 


\section{Kesimpulan dan Saran}

\subsection{Kesimpulan}

Setelah melalui serangkaian tahapan dalam penelitian ini mulai dari identifikasi masalah hingga tahap penerapan algoritma Watermarking image ke dalam file pdf dapat disimpulkan:

1. Sistem dapat diterapkan atau digunakan dosen maupun pihak LP2S UMI untuk memberi tanda kepemilikan dokumen yang dimilikinya.

2. Sistem dapat memberikan layanan tambahan dalam pengecekan kemiripan judul yang telah ada sebelumnya di LP2S.

\subsection{Saran}

Sistem yang dirancang dalam penelitian ini masih memiliki beberapa kelemahan dan kekurangan, dengan harapan peneliti selanjutnya dapat mengembangkan atau melengkapi, adapun sarannya adalah

1. Selain Watermarking image atau gambar dapat ditambahkan layanan Watermarking text untuk file PDF.

2. Proses pengecekan kemiripan judul diberikan tambahan layanan pemberian nilai tolerance untuk dapat dibandingkan dalam mengukur kemiripan setiap kata.

\section{Daftar Pustaka}

[1] Cachin, C. (2005). Digital Steganography. Encyclopedia of Cryptography and Security.

[2] Gunawan H (2014). Dosen lebih Suka menjiplak, http://www.tribunnews.com/nasional/2014/06/04/dosen-lebih-suka-meniiplak-tahun-lalu-ada-808kasus-plagiarisme. diakses pada tanggal 24 Maret 2015.

[3] James Gosling, Bill Joy, Guy Steele, and Gilad Bracha (2005). "The Java LanguageSpecification, 2nd Edition"

[4] Kemdikbud (2008), Kamus Besar Bahasa Indonesia, http://badanbahasa.kemdikbud.go.id/kbbi/index.php diakses pada tanggal 14 Desember 2015

[5] Mohanty, S.P. (1999). Digital Watermarking: A Tutorial review

[6] Permendiknas no 17 tahun 2013, Pencegahan dan Penanggulangan Plagiat di perguruan Tinggi. 